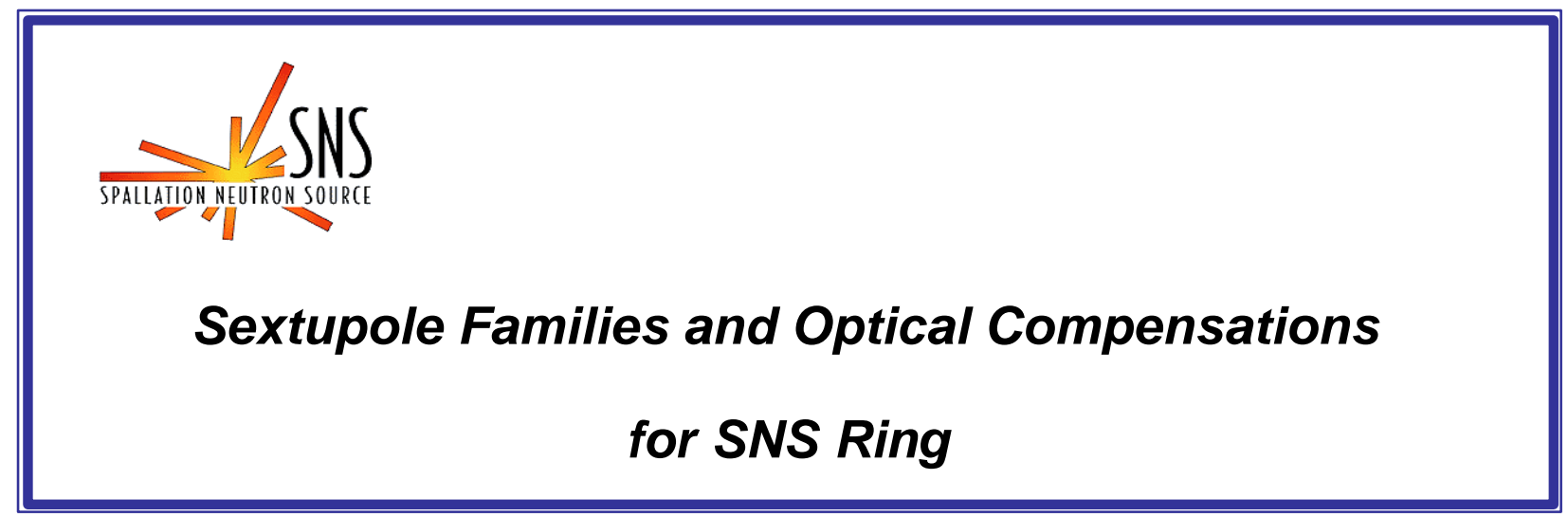

BNL/SNS TECHNICAL NOTE

NO. 096

N. Tsoupas, J. Wei, C.J. Gardner, Y.Y. Lee

July 17, 2001

COLLIDER-ACCELERATOR DEPARTMENT

BROOKHAVEN NATIONAL LABORATORY

UPTON, NEW YORK 11973 


\title{
Sextupole Families and Optical Compensations for SNS Ring
}

\author{
N. Tsoupas , J. Wei, C.J. Gardner, Y.Y. Lee \\ Brookhaven National Laboratory, Upton, NY 11973
}

\begin{abstract}
The accumulator ring of the Spallation Neutron Source (SNS) is designed to accumulate in a single bunch $2.1 \times 10^{14}$ protons, with uncontrolled beam losses $\leq 10^{-4}$. The accumulated single bunch length will be $\sim 590 \mathrm{nsec}$ with a proton energy of $1 \mathrm{GeV}$ to $1.3 \mathrm{GeV}$. The large transverse emittance of the circulating beam $(160 \pi . \mathrm{mm} . \mathrm{mrad}$ at $95 \%$ beam intensity) may bring part of the beam into undesirable resonance. In order to avoid such resonances, four families ${ }^{1}$ of sextupoles will be placed in the arcs of the SNS accumulator, to control the chromaticity of the ring and also minimize the dependence of the optical properties of the ring on the momentum spread of the beam. In this paper we describe the method of chromaticity control and the compensation of the ring's optical properties, and provide the sextupole strength required to control the value of the chromaticity over a wide range.
\end{abstract}

\section{Introduction}

The accumulator ring of the Spallation Neutron Source (SNS) [1] is designed to accumulate high intensity $\left(2.1 \times 10^{14}\right.$ protons) in a single bunch at an energy of 1.0 to $1.3 \mathrm{GeV}$. The accumulated bunch will be $\sim 590 \mathrm{nsec}$ long and will circulate in the ring for $\sim 1.2 \mathrm{msec}$ with a $\mathrm{f}_{\text {rev }} \cong 1.05 \mathrm{MHz}$, before it is extracted [2] into the RTBT transfer line [3] which will transport the beam bunch to the SNS target. A schematic diagram of a super-period (one quarter) of the SNS accumulator ring with the location of the main magnetic elements (dipoles, tune-quadrupoles, chromatic-sextupoles and correctors is shown in figure 1).

The average beam power stored in the beam bunch will be $\sim 2 \mathrm{MW}$ at $1.3 \mathrm{GeV}$ proton energy with a repetition rate of $60 \mathrm{~Hz}$. Such a high beam power requires optimum design of the accumulator ring, that must generate low uncontrolled beam losses of $\leq 10^{-4}$ at $1.3 \mathrm{GeV}$ proton energy. An additional factor that puts even stricter requirement on the design of the ring is the large transverse emittance $\left(\varepsilon_{\mathrm{x}}=\varepsilon_{\mathrm{y}}=160 \pi \mathrm{mm} . \mathrm{mrad}\right.$ at $\left.95 \%\right)$ and large momentum spread $(\delta \mathrm{p} / \mathrm{p}= \pm 0.6 \%)$ of the circulating beam. It is well known that beam bunches with large transverse size and large momentum spread may bring part of the beam into resonance and/or may generate beam instabilities that will induce beam losses.

One of the design aspects that will help avoid beam resonances and/or beam instabilities of the circulating beam and therefore minimize the uncontrolled beam losses in the accumulator ring, is optics control'.

This paper discusses the method for chromaticity control ${ }^{3}$ of the ring and the necessity for optical compensation ${ }^{4}$ by using four families of sextupoles along the ring.

\footnotetext{
${ }^{1}$ A single family of sextupoles is defined here as the sextupoles (one or more per superperiod) which are powered in series. The sextupoles of each family appear at the same locations in every superperiod of the ring.

${ }^{2}$ Optics control is the ability to control the tunes $\left(\mathrm{Q}_{\mathrm{x}}, \mathrm{Q}_{\mathrm{y}}\right)$ and the chromaticities $\left(\xi_{\mathrm{x}} \xi_{\mathrm{y}}\right)$ of the synchrotron.

${ }^{3}$ The term chromaticity refers to the first derivative of the tune with respect to the momentum spread devided by the tune. $\xi_{\mathrm{x}}=\left\{\vartheta \mathrm{Q}_{\mathrm{x}} /\left.\vartheta(\delta \mathrm{p} / \mathrm{p})\right|_{\delta \mathrm{p}=0}\right\} / \mathrm{Q}_{\mathrm{x}}, \quad \xi_{\mathrm{y}}=\left\{\vartheta \mathrm{Q}_{\mathrm{y}} /\left.\vartheta(\delta \mathrm{p} / \mathrm{p})\right|_{\delta \mathrm{p}=0}\right\} / \mathrm{Q}_{\mathrm{y}}$
} 
For a particular working point $\left(\mathrm{Q}_{\mathrm{x}}=6.3, \mathrm{Q}_{\mathrm{y}}=5.8\right)$ of the ring a table will be provided with the required field strength for each sextupole family that achieves both, a given chromatic correction, and optimum optical compensation.

\section{Chromaticity control and optical compensation.}

The chromaticity function of a synchrotron ring is defined as the first derivative of the tune with respect to the momentum $\xi_{\mathrm{x}}=\vartheta \mathrm{Q}_{\mathrm{x}} /\left.\vartheta(\delta \mathrm{p} / \mathrm{p})\right|_{\delta \mathrm{p}=0} / \mathrm{Q}_{\mathrm{x}}, \quad \xi_{\mathrm{y}}=\vartheta \mathrm{Q}_{\mathrm{y}} /\left.\vartheta(\delta \mathrm{p} / \mathrm{p})\right|_{\delta \mathrm{p}=0} / \mathrm{Q}_{\mathrm{y}}$. For a synchrotron the chromaticity function is given by [4]:

$$
\begin{array}{ll}
\xi_{\mathrm{r}, \mathrm{N}}=-\frac{1}{4 \pi} \oint \boldsymbol{\beta}_{\mathrm{r}}(s) k_{0}(s) d s & 1.1 \\
\xi_{\mathrm{Y}, \mathrm{N}}=-\frac{1}{4 \pi} \oint \boldsymbol{\beta}_{\mathrm{r}}\left(s_{\mathrm{r}}\right) k_{0}(s) d s & 1.2
\end{array}
$$

In equations 1.1 and 1.2, $\beta_{\mathrm{x}}$, and $\beta_{\mathrm{y}}$ are the horizontal and vertical beta functions of the ring, and $\mathrm{k}_{0}(\mathrm{~s})=\mathrm{G}(\mathrm{s}) /(\mathrm{B} \rho)$ is the ratio of the gradient $\left\{\mathrm{G}(\mathrm{s})=\mathrm{B}_{\text {pole-tip }} /\right.$ radius $\}$ of the quadrupoles along the ring over the beam rigidity $(\mathrm{B} \rho)$. The integration is along the central orbit of the beam.

The chromaticity function defined by 1.1 and 1.2 is also called the "natural chromaticity" of the ring. In a synchrotron with a regular FODO lattice and no straight sections (apart from those included in the FODO cell), the natural chromaticities $\xi_{\mathrm{x}, \mathrm{N}}$ and $\xi_{\mathrm{y}, \mathrm{N}}$ are equal and opposite in value to the tunes $\mathrm{Q}_{\mathrm{x}}$ and $\mathrm{Q}_{\mathrm{y}}$ respectively.

A method to control the natural chromaticity of a synchrotron, while keeping the tunes $Q_{x}$ and $Q_{y}$ constant, is to introduce two families of multipoles (higher then quadrupole) along the ring. Two families of sextupoles ${ }^{5}$ for example placed at locations of the ring where the dispersion function is nonzero, will affect the chromaticity of the ring by an amount given [4] by the equations 2.1 and 2.1 below.

$$
\begin{array}{ll}
\xi_{x, \mathrm{~s}}=-\frac{1}{2 \pi} \oint \boldsymbol{\beta}(s) \boldsymbol{b}_{2}(s) \boldsymbol{\eta}_{x}(s) d s & \mathbf{2 . 1} \\
\xi_{\mathrm{y}, \mathrm{s}}=-\frac{1}{2 \pi} \oint \boldsymbol{\beta}(s) \boldsymbol{b}_{2}(s) \boldsymbol{\eta}_{x}(s) d s & \mathbf{2 . 2}
\end{array}
$$

In the equations 2.1 and 2.2 the symbol $\eta_{\mathrm{x}}$ is the horizontal dispersion function of the ring. The vertical dispersion function $\eta_{y}$ of the ring is assumed here to be zero. The symbol $b_{2}(s)$ is the sextupole "Gradiend" strength along the ring and is related to the $y$-component of the sextupole magnetic field $\mathrm{B}_{\mathrm{y}}(\mathrm{s}, \mathrm{x})$ by the relation $\mathrm{B}_{\mathrm{y}}(\mathrm{s}, \mathrm{x})=\mathrm{b}_{2}(\mathrm{~s}) \mathrm{x}^{2}$

With the chromaticity sextupoles turned on, the total horizontal and vertical chromaticities are the sums of the "natural chromaticity" \{Eq. 1.1, 1.2 \} and the "sextupole generated" $\{$ Eq. 2.1, 2.2 $\}$ chromaticities, namely:

$$
\begin{array}{ll}
\xi_{\mathrm{x}, \mathrm{T}}=\xi_{\mathrm{x}, \mathrm{N}}+\xi_{\mathrm{x}, \mathrm{S}} & 3.1 \\
\xi_{\mathrm{y}, \mathrm{T}}=\xi_{\mathrm{y}, \mathrm{N}}+\xi_{\mathrm{y}, \mathrm{S}} & 3.2
\end{array}
$$

\footnotetext{
${ }^{4}$ Optical compensation refers to the minimization of the derivatives with respect to the momentum spread of the beam, of the various optical functions $\left(\beta_{\mathrm{x}}, \beta_{\mathrm{y}}, \eta_{\mathrm{x}}, \xi_{\mathrm{x}}, \xi_{\mathrm{y}}\right)$ of the ring $\left(\vartheta \beta_{\mathrm{x}} /\left.\vartheta(\delta \mathrm{p} / \mathrm{p})\right|_{\delta \mathrm{p}=0}\right.$, $\vartheta \beta_{\mathrm{y}} /\left.\vartheta(\delta \mathrm{p} / \mathrm{p})\right|_{\delta \mathrm{p}=0}, \vartheta \eta_{\mathrm{x}} /\left.\vartheta(\delta \mathrm{p} / \mathrm{p})\right|_{\delta \mathrm{p}=0},\left(\vartheta^{2} \mathrm{Q}_{\mathrm{x}} /\left.\vartheta(\delta \mathrm{p} / \mathrm{p})^{2}\right|_{\delta \mathrm{p}=0},\left(\vartheta^{2} \mathrm{Q}_{\mathrm{x}} /\left.\vartheta(\delta \mathrm{p} / \mathrm{p})^{2}\right|_{\delta \mathrm{p}=0}\right)\right.$.

${ }^{5}$ These sextupoles are also referred to as chromaticity sextupoles.
} 
The total chromaticity functions $\xi_{\mathrm{x}, \mathrm{T}}, \xi_{\mathrm{y}, \mathrm{T}}$ can be controlled by varying the values of $\xi_{\mathrm{x}, \mathrm{S}}, \xi_{\mathrm{y}, \mathrm{S}}$ which can be done by varying the field strength $b_{2}(s)$ of the chromaticity sextupoles .

The use of two families of sextupoles, which are placed at locations of the ring where the values of the functions $\beta_{x, y}$ and $\eta_{x}$ are high, can control the chromaticity of the ring.

The sextupoles however may strongly affect the first and second order dependence, on the momentum spread of the $\beta_{x, y}$ and $\eta_{x}$ functions as well as of the chromaticity, shown by the equations 4, 5, and 6 below. A method to derive explicit expressions of the first and higher order derivatives appearing in equations $4,5,6$ in terms of the $\left(\beta_{x, 0}(s), \beta_{y, 0}(s), \eta_{x, 0}(s), k_{0}, b_{2}\right)$ is given in Ref. [4].

$$
\begin{array}{ll}
\beta_{\mathrm{x}}(\mathrm{s}, \delta \mathrm{p})=\beta_{\mathrm{x}, 0}(\mathrm{~s})+\left[\vartheta \beta_{\mathrm{x}} /\left.\vartheta(\delta \mathrm{p} / \mathrm{p})\right|_{\delta \mathrm{p}=0}\right](\delta \mathrm{p} / \mathrm{p})+\left[\vartheta^{2} \beta_{\mathrm{x}} /\left.\vartheta(\delta \mathrm{p} / \mathrm{p})^{2}\right|_{\delta \mathrm{p}=0}\right](\delta \mathrm{p} / \mathrm{p})^{2} & 4.1 \\
\beta_{\mathrm{y}}(\mathrm{s}, \delta \mathrm{p})=\beta_{\mathrm{y}, 0}(\mathrm{~s})+\left[\vartheta \beta_{\mathrm{y}} /\left.\vartheta(\delta \mathrm{p} / \mathrm{p})\right|_{\delta \mathrm{p}=0}\right](\delta \mathrm{p} / \mathrm{p})+\left[\vartheta^{2} \beta_{\mathrm{y}} /\left.\vartheta(\delta \mathrm{p} / \mathrm{p})^{2}\right|_{\delta \mathrm{p}=0}\right](\delta \mathrm{p} / \mathrm{p})^{2} & 4.1 \\
\eta_{\mathrm{x}}(\mathrm{s}, \delta \mathrm{p})=\eta_{\mathrm{x}, 0}(\mathrm{~s})+\left[\vartheta \eta_{\mathrm{x}} /\left.\vartheta(\delta \mathrm{p} / \mathrm{p})\right|_{\delta \mathrm{p}=0}\right](\delta \mathrm{p} / \mathrm{p})+\left[\vartheta^{2} \eta_{\mathrm{x}} /\left.\vartheta(\delta \mathrm{p} / \mathrm{p})^{2}\right|_{\delta \mathrm{p}=0}\right](\delta \mathrm{p} / \mathrm{p})^{2} & 5.1 \\
\xi_{\mathrm{x}, \mathrm{T}}(\delta \mathrm{p} / \mathrm{p})=\xi_{\mathrm{x}, \mathrm{T}}(0)+\left[\vartheta \xi_{\mathrm{x}} /\left.\vartheta(\delta \mathrm{p} / \mathrm{p})\right|_{\delta \mathrm{p}=0}\right](\delta \mathrm{p} / \mathrm{p})+\left[\vartheta^{2} \xi_{\mathrm{x}} /\left.\vartheta(\delta \mathrm{p} / \mathrm{p})^{2}\right|_{\delta \mathrm{p}=0}\right](\delta \mathrm{p} / \mathrm{p})^{2} & 6.1 \\
\xi_{\mathrm{y}, \mathrm{T}}(\delta \mathrm{p} / \mathrm{p})=\xi_{\mathrm{y}, \mathrm{T}}(0)+\left[\vartheta \xi_{\mathrm{y}} /\left.\vartheta(\delta \mathrm{p} / \mathrm{p})\right|_{\delta \mathrm{p}=0}\right](\delta \mathrm{p} / \mathrm{p})+\left[\vartheta^{2} \xi_{\mathrm{y}} /\left.\vartheta(\delta \mathrm{p} / \mathrm{p})^{2}\right|_{\delta \mathrm{p}=0}\right](\delta \mathrm{p} / \mathrm{p})^{2} & 6.1
\end{array}
$$

This dependence of the functions $\beta_{\mathrm{x}, \mathrm{y}}$ and $\eta_{\mathrm{x}}$ on $\delta \mathrm{p} / \mathrm{p}$ may introduce strong "beta/dispersion waves", which will reduce the dynamic aperture of the ring.

In addition the "beta/dispersion waves" will affect the horizontal and vertical chromaticities $\xi_{\mathrm{x}, \mathrm{T}}(\delta \mathrm{p})$ and $\xi_{\mathrm{y}, \mathrm{T}}(\delta \mathrm{p})$ through the first and higher order terms of the chromaticity expression [4] given by equation 6 .

In order to minimize the dependence of the beta, the dispersion functions and the chromaticity on the $(\delta \mathrm{p} / \mathrm{p})$, additional families of sextupoles are required.

The next section shows how a family of four sextupoles, placed at locations of the ring with non zero dispersion, can be used to control the chromaticity and minimize the various derivatives (expansion coefficients appearing in eqs. 4,5,6) of the functions $\eta_{\mathrm{x}}(\mathrm{s}, \delta \mathrm{p} / \mathrm{p}), \beta_{\mathrm{x}, \mathrm{y}}(\mathrm{s}, \delta \mathrm{p} / \mathrm{p})$, and $\xi_{\mathrm{x}, \mathrm{y}}(\delta \mathrm{p} / \mathrm{p})$ with respect to $(\delta \mathrm{p} / \mathrm{p})$.

\section{Why four families of sextupoles.}

The equations 3.1 and 3.2 show that two families of sextupoles are necessary and sufficient to control the chromaticity in a synchrotron. Additional families of sextupoles however are needed to minimize the dependence of the functions $\beta_{\mathrm{x}}, \beta_{\mathrm{y}}, \eta_{\mathrm{x}}$ and $\xi_{\mathrm{x}, \mathrm{T}}, \xi_{\mathrm{y}, \mathrm{T}}$ on the $\delta \mathrm{p} / \mathrm{p}$.

A convincing justification of the above statement, for the case of the SNS accumulator ring, is given in this section.

The computation of the chromaticities and the various derivatives appearing in equations 4,5,6 were performed using the MAD computer code [5], which make use of the formalism of Ref. [4]. The minimization process of the various derivatives appearing in equations 4,5,6 is also done within the MAD computer code.

For the particular working point $\left(\mathrm{Q}_{\mathrm{x}}=6.3 \mathrm{Q}_{\mathrm{y}}=5.8\right)$ of the SNS accumulator ring the natural chromaticities are calculated to be $\xi_{\mathrm{x}, \mathrm{N}}=-7.74$ and $\xi_{\mathrm{y}, \mathrm{N}}=-6.40$. The $\beta_{\mathrm{x}, \mathrm{y}}$ and $\eta_{\mathrm{x}}$ functions as a function of distance covering one super-period of the accumulator ring are shown in figure 2 , for three different values of momentum spread of the beam $\delta \mathrm{p} / \mathrm{p}(-0.6 \%, 0 \%$ and $+0.6 \%)$. It appears from figure 2 that when the chromaticity sextupoles are off (the chromaticity of the ring is the natural chromaticity), the $\beta_{\mathrm{x}, \mathrm{y}}$ and $\eta_{\mathrm{x}}$ functions for particles with nonzero $\delta \mathrm{p} / \mathrm{p}$ do not depend strongly on the $\delta \mathrm{p} / \mathrm{p}$. 
Suppose now that we want to keep the same tunes but to change the horizontal and vertical chromaticities of the ring to $\left.\xi_{\mathrm{x}, \mathrm{T}}\right|_{\delta \mathrm{p} / \mathrm{p}=0}=0.0$ and $\left.\xi_{\mathrm{y}, \mathrm{T}}\right|_{\delta \mathrm{\rho} / \mathrm{p}=0}=0.0$.

This change of the chromaticities can be done by using only two families of chromaticity sextupoles and in particular the sextupoles labeled S2(F2) and S3(F3) which are shown in figure 3 . The sextupoles are placed at location of the ring with high values of the $\beta_{x, y}$ and $\eta_{x}$ functions. The new desired chromaticities namely $\left.\xi_{\mathrm{x}, \mathrm{T}}\right|_{\delta \mathrm{p} / \mathrm{p}=0}=0.0$ and $\left.\xi_{\mathrm{y}, \mathrm{T}}\right|_{\delta \mathrm{p} / \mathrm{p}=0}=0.0$ (Eq. 3.1 3.2) can be achieved by adjusting the strength of each sextupole family.

The result of the effect of the two family sextupoles on the chromaticity functions is shown in figure 4 , where the values of the functions $\xi_{\mathrm{x}, \mathrm{T}}$ and $\xi_{\mathrm{y}, \mathrm{T}}$ are indeed equal to zero for $\delta \mathrm{p} / \mathrm{p}=0$, as requested. There is however a strong $\delta \mathrm{p} / \mathrm{p}$ dependence of the chromaticity functions $\xi_{\mathrm{x}, \mathrm{T}}(\delta \mathrm{p} / \mathrm{p})$ (thick continuous line with large slope and curvature in figure 4 ), and $\xi_{\mathrm{y}, \mathrm{T}}(\delta \mathrm{p} / \mathrm{p})$ (thick dashed line with large slope and curvature in figure 4). Another undesired effect of using only two families of sextupoles to control the chromaticity functions, is shown in figure 3 which plots the $\beta_{x, y}$ and $\eta_{x}$ functions along a superperiod of the ring for three different momenta spread $\delta \mathrm{p} / \mathrm{p}(-0.6 \%, 0 \%$ and $+0.6 \%$ ). The figures 3 and 4 demonstrate that the contribution of the higher order terms in Eqs. 4,5,6 is significant, therefore two families of sextupoles are inadequate to minimize these higher order terms while keeping the desired chromaticity values, in this case $\xi_{\mathrm{x}, \mathrm{T}} \delta_{\delta \mathrm{p} / \mathrm{p}=0}=0.0$ and $\xi_{\mathrm{y}, \mathrm{T} \mid \delta \mathrm{p} / \mathrm{p}=0}=0.0$.

The consequence of the strong "beta wave" which is shown in figure 3 reduces the dynamic aperture of the accumulator ring, it also affects the chromaticity functions of the ring by introducing strong dependence of the functions $\xi_{\mathrm{x}, \mathrm{T}}$ and $\xi_{\mathrm{y}, \mathrm{T}}$ on $\delta \mathrm{p} / \mathrm{p}$, (see figure 4 ) thus bringing the beam closer to resonance condition.

In order to optically compensate the strong dependence of the $\beta_{x, y}$ and $\eta_{x}$ functions on $\delta p / p$, a set of two additional sextupole families is introduced in the ring. The location of each sextupole family in each super-period is shown in figure 5. The first sextupole $\mathrm{S} 1(\mathrm{~F} 1)$ and the last $\mathrm{S} 5(\mathrm{~F} 1)$ shown in figure 5 belong to the same family $(\mathrm{F} 1)$, with the rest of the sextupoles $\mathrm{S} 2(\mathrm{~F} 2), \mathrm{S} 3(\mathrm{~F} 3)$ and $\mathrm{S} 4(\mathrm{~F} 4)$ forming a sextupole family each.

As in the case of two family sextupoles, the values of the chromaticity functions $\left.\xi_{\mathrm{x}, \mathrm{T}}\right|_{\delta \mathrm{p} / \mathrm{p}=0}$ and $\xi_{\mathrm{y}, \mathrm{T} \mid \delta \mathrm{p} / \mathrm{p}=0}$ are indeed zero as shown in figure 4 with the additional benefit that the chromaticity functions $\xi_{\mathrm{x}, \mathrm{T}}(\delta \mathrm{p} / \mathrm{p})$ (thin continuous line, almost horizontal with small curvature shown in figure $4)$, and $\xi_{\mathrm{y}, \mathrm{T}}(\delta \mathrm{p} / \mathrm{p})$ (thin dashed almost horizontal with small curvature shown in figure 4) do not depend strongly on $\delta \mathrm{p} / \mathrm{p}$ in contrast with the case of two family sextupoles.

Another beneficial effect of the four family sextupoles is shown in figure 5 which plots the $\beta_{x, y}$ and $\eta_{\mathrm{x}}$ functions along a super-period of the ring, for the three different momentum spreads $\delta \mathrm{p} / \mathrm{p}$ $(-0.6 \%, 0 \%$ and $+0.6 \%)$ of the beam. This plot demonstrates that the four families of sextupoles, reduce significantly the dependence of the $\beta_{\mathrm{x}, \mathrm{y}}$ and $\eta_{\mathrm{x}}$ functions on $\delta \mathrm{p} / \mathrm{p}$.

A comparison of the plot of the $\beta_{x, y}$ and $\eta_{x}$ functions shown in figure 3 which corresponds to the case of two family sextupoles, and the plot of the $\beta_{x, y}$ and $\eta_{x}$ functions shown in figure 5 , which corresponds to the case of four family sextupoles, demonstrates that the four family sextupoles reduce significantly the dependence of the $\beta_{x, y}$ and $\eta_{x}$ functions on $\delta p / p$.

The four family sextupoles can help maintain a dynamical aperture independent of the chromaticity of the ring, and also keep the beam away from resonances by having control on the chromaticity functions over a wide range of $\delta \mathrm{p} / \mathrm{p}$.

\section{Chromaticity and optical compensation range of the SNS accumulator ring using four family sextupoles.}

It is not an easy task to calculate an optimum working point $\left(\mathrm{Q}_{\mathrm{x}}, \mathrm{Q}_{\mathrm{y}}\right)$ and chromaticity $\left(\xi_{\mathrm{x}, \mathrm{T}}, \xi_{\mathrm{y}, \mathrm{T}}\right)$ for the SNS accumulator ring which will be free of resonances and beam instabilities. 
It is advisable therefore to study the range of the chromaticities that the accumulator ring can attain by varying the strength of each of the four family sextupoles mentioned earlier.

This study which is similar to the study of the previous section, was accomplished using the MAD computer code and the results are shown in TABLE I.

Each horizontal line of the TABLE I corresponds to the chromaticity settings ${ }^{5}$ (first and second columns) followed by the values $\mathrm{L}^{*} \mathrm{~K} 2^{6}$ of each of the four families of sextupoles (columns 3 to 6) which are required to provide the chromaticities settings shown in the first and second columns. Part of the optical compensation which is accomplished by the four family sextupoles is the minimization of the first and second order terms in equations 6.1 and 6.2 .

The effect on minimizing these terms is shown in figure 6, were the chromaticities of the ring $\xi_{\mathrm{x}, \mathrm{T}}(\delta \mathrm{p} / \mathrm{p})$, and $\xi_{\mathrm{y}, \mathrm{T}}(\delta \mathrm{p} / \mathrm{p})$ for each setting of the four family sextupoles (see TABLE I) are plotted $^{7}$ as a function of $\delta \mathrm{p} / \mathrm{p}$, and show no strong dependence on $\delta \mathrm{p} / \mathrm{p}$. The values of the chromaticity sextupoles appearing in TABLE I not only set the desired chromaticities functions $\left.\xi_{\mathrm{x}, \mathrm{T}}\right|_{\delta \mathrm{p} / \mathrm{p}=0}$ and $\left.\xi_{\mathrm{y}, \mathrm{T}}\right|_{\delta \mathrm{p} / \mathrm{p}=0}$ of the ring at a particular value, but also remove the dependence of the chromaticity functions $\xi_{\mathrm{x}, \mathrm{y}}(\delta \mathrm{p} / \mathrm{p})$ and $\beta_{\mathrm{x}, \mathrm{y}}$, and $\eta_{\mathrm{x}}$ functions on $\delta \mathrm{p} / \mathrm{p}$ as shown in figures 4,5 and 6 .

Table I: Strength of sextupole families to achieve given chromaticities and optical compensation

\begin{tabular}{|c|c|c|c|c|c|}
\hline$\left.\xi_{\mathrm{x}, \mathrm{T}}\right|_{\delta \mathrm{p} / \mathrm{p}=0}$ & $\left.\xi_{\mathrm{y}, \mathrm{T}}\right|_{\delta \mathrm{p} / \mathrm{p}=0}$ & $\mathrm{~S} 1(\mathrm{~F} 1) / \mathrm{S} 5(\mathrm{~F} 1)$ & $\mathrm{S} 2(\mathrm{~F} 2)$ & $\mathrm{S} 3(\mathrm{~F} 3)$ & $\mathrm{S} 4(\mathrm{~F} 4)$ \\
\hline & & $\mathrm{K} 2\left[\mathrm{~m}^{-3}\right]$ & $\mathrm{K} 2\left[\mathrm{~m}^{-3}\right]$ & $\mathrm{K} 2\left[\mathrm{~m}^{-3}\right]$ & $\mathrm{K} 2\left[\mathrm{~m}^{-3}\right]$ \\
\hline-12 & -12 & 1.8579 & -1.5113 & 4.1001 & -2.1237 \\
\hline-10 & -10 & 1.1248 & -1.5113 & 2.5963 & -5.2898 \\
\hline-8 & -8 & 2.8070 & -2.3894 & 1.2412 & -2.0964 \\
\hline-7.74 & -6.4 & 0.0 & 0.0 & 0.0 & 0.0 \\
\hline-5 & -5 & -0.83216 & 0.6314 & -0.9969 & 1.3118 \\
\hline-4 & -4 & -1.7596 & 1.4133 & -0.9969 & 1.3118 \\
\hline-3 & -3 & -1.6942 & 1.3898 & -2.3279 & 2.1446 \\
\hline-2 & -2 & -2.1443 & 2.3468 & -2.9679 & 1.9826 \\
\hline-1 & -1 & -2.0173 & 2.3468 & -4.3815 & 2.7935 \\
\hline 0 & 0 & -2.4319 & 3.2055 & -5.0690 & 2.7309 \\
\hline 1 & 1 & -2.7535 & 3.5424 & -5.9273 & 3.1936 \\
\hline
\end{tabular}

An example of the section of the MAD input file which deals with the minimization process mentioned earlier is included in the APPENDIX I.

Figure 7 plots the $\mathrm{L}^{*} \mathrm{~K} 2$ values (which appear in TABLE I) of each family of sextupoles versus the chromaticity values $\left(\xi_{\mathrm{x}, \mathrm{T}}=\xi_{\mathrm{x}, \mathrm{T}}\right)$ which attained by this set of $\mathrm{L} * \mathrm{~K} 2$ values.

\section{Conclusion}

We have demonstrated that four families of sextupoles could set the values of chromaticity functions of the ring over a wide range, and also remove the dependence of the of the chromaticity functions $\xi_{\mathrm{x}, \mathrm{y}}(\delta \mathrm{p} / \mathrm{p})$ and $\beta_{\mathrm{x}, \mathrm{y}}$, and $\eta_{\mathrm{x}}$ functions on $\delta \mathrm{p} / \mathrm{p}$. Such a tool may prove very valuable in operating the accumulator ring away from beam resonance conditions or beam instabilities.

\footnotetext{
${ }^{5}$ In this study we required that the horizontal chromaticity to be equal with the vertical $\left(\xi_{\mathrm{x}}=\xi_{\mathrm{y}}\right)$.

${ }^{6} \mathrm{~L}$ is the Effective length of the sextupole, and $\mathrm{K} 2=2\left(\mathrm{~B}_{0} / \mathrm{a}^{2}\right) /(\mathrm{B} \rho)$ with $\mathrm{B}_{0}=$ Pole tip field, a=Radius of sextupole aperture, $\mathrm{B} \rho=$ rigidity of the beam.

${ }^{7}$ Note the small slope and curvature of the functions $\xi_{\mathrm{x}, \mathrm{T}}(\delta \mathrm{p} / \mathrm{p})$, and $\xi_{\mathrm{y}, \mathrm{T}}(\delta \mathrm{p} / \mathrm{p})$
} 
[1] J. Wei et al. A FODO/Doublet Lattice for the SNS Accumulator Ring. These proceedings.

[2] N. Tsoupas et al. Beam Extraction from the SNS Ring and Design of Extraction Kickers. These proceedings.

[3] D. Raparia et al. The Design Issues in the SNS Transfer Lines. These Proceedings.

[4] E. D. Courant and H. S. Snyder. Theory of alternating gradient synchrotron. Annals of Physics, 3:1-48, 1958.

[5] The MAD Program. User's Reference Manual. CERN/SL/90-13 (AP) 


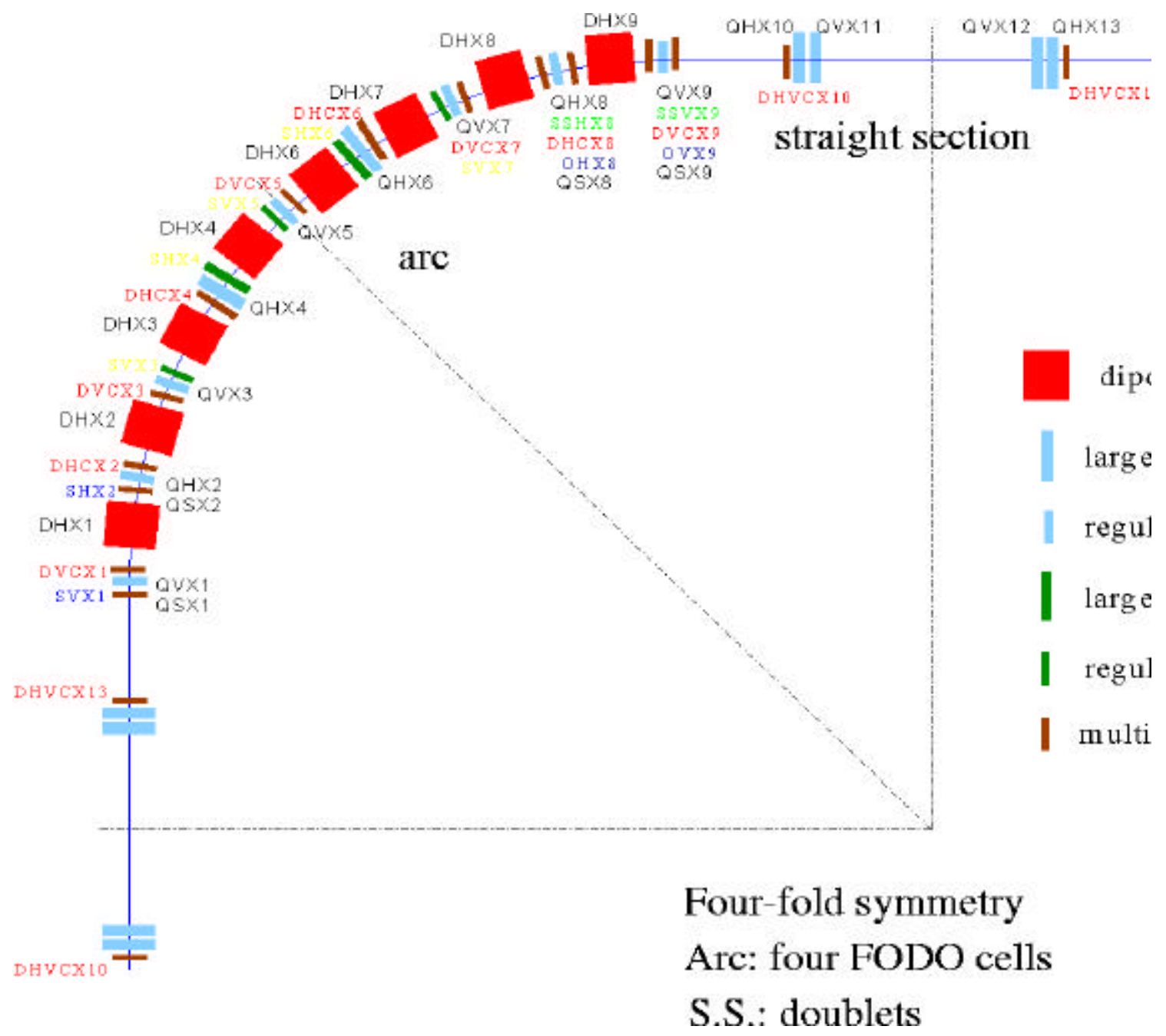

Figure 1: Schematic Layout of the magnetic elements over one quarter (one super-period) of the SNS Ring. 


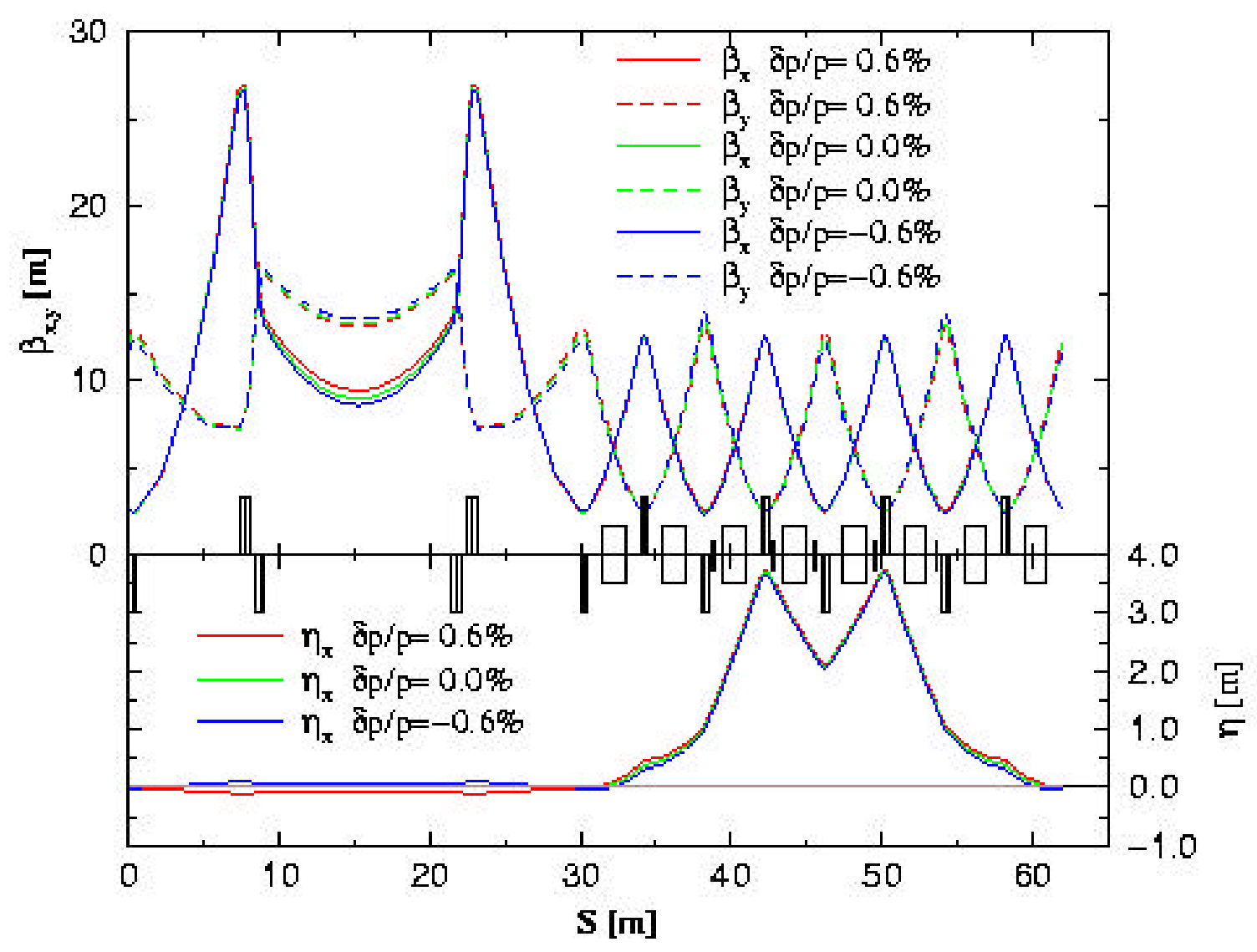

Figure 2. Plot of the optical functions $\beta_{\mathrm{x}, \mathrm{y}}$ and $\eta_{\mathrm{x}}$ for three different momenta $\delta \mathrm{p} / \mathrm{p}$ $(-0.6 \%, 0 \%$ and $+0.6 \%)$ along a superperiod of the SNS ring. None of the sextupole families is on. The plot of the optical functions $\beta_{\mathrm{x}, \mathrm{y}}$ and $\eta_{\mathrm{x}}$ shows that there no strong dependence of these functions on $\delta \mathrm{p} / \mathrm{p}$. 


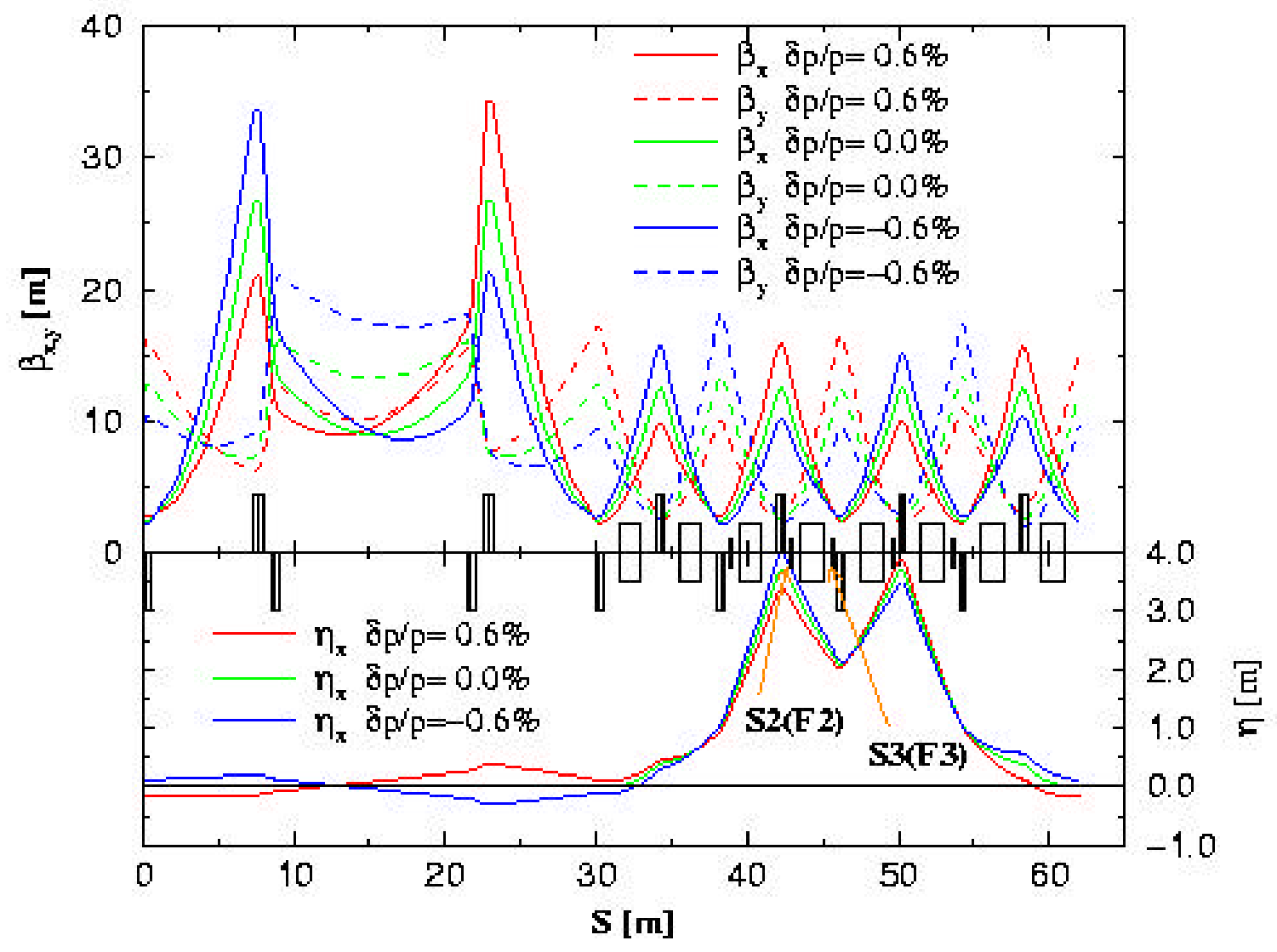

Figure 3. Plot of the optical functions $\beta_{x, y}$ and $\eta_{x}$ for three different momenta $\delta p / p$ $(-0.6 \%, 0 \%$ and $+0.6 \%)$ along a superperiod of the SNS ring. The two families of sextupoles $\mathrm{S} 2(\mathrm{~F} 2)$ and S3(F3) are on to set the chromaticities $\left.\xi_{\mathrm{x}, \mathrm{T}}\right|_{\delta \mathrm{p} / \mathrm{p}=0}=0.0$ and $\left.\xi_{\mathrm{y}, \mathrm{T}}\right|_{\delta \mathrm{p} / \mathrm{p}=0}=0.0$. This plot shows that there is strong dependence of the optical functions $\beta_{\mathrm{x}, \mathrm{y}}$ and $\eta_{\mathrm{x}}$ on $\delta \mathrm{p} / \mathrm{p}$. 


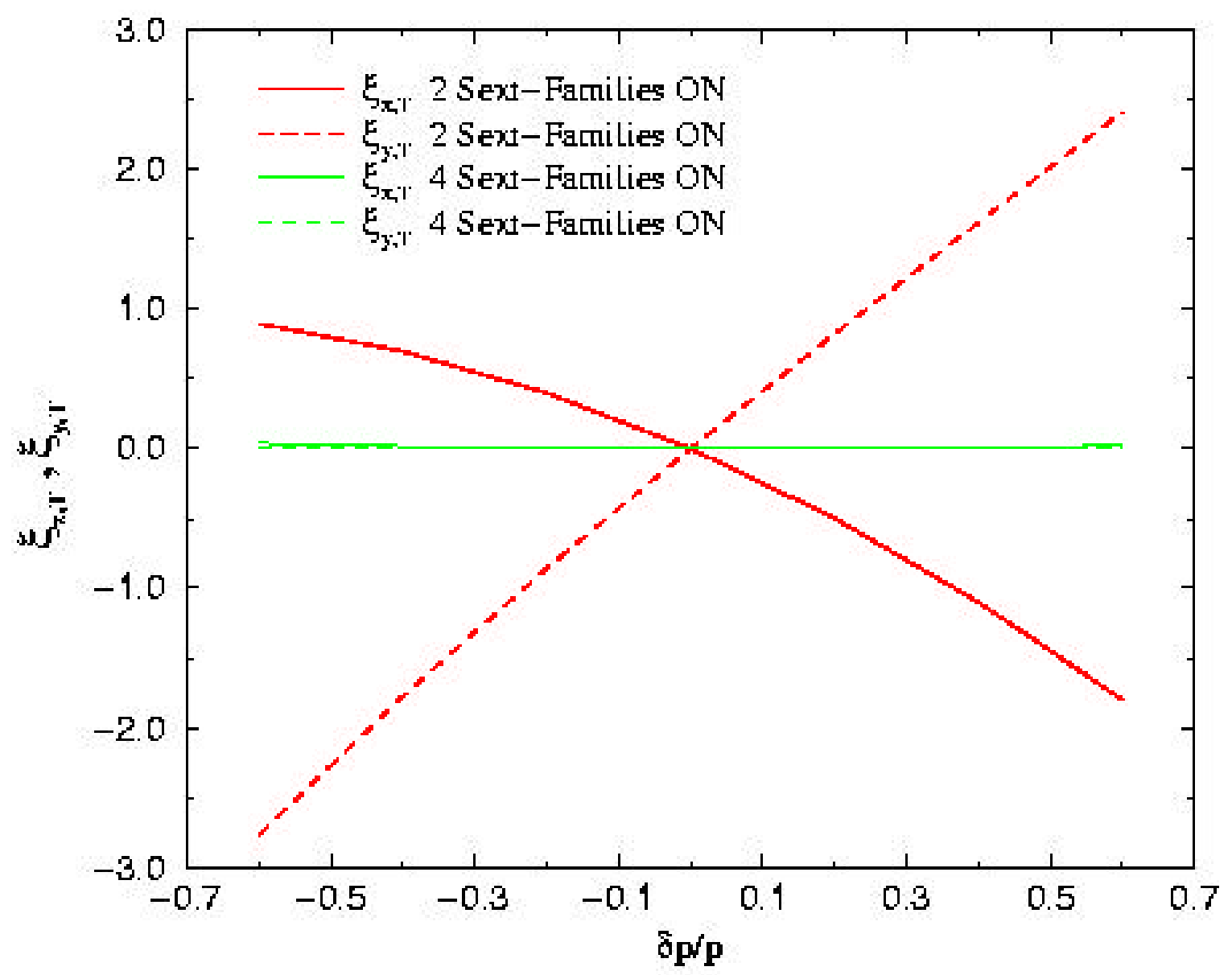

Figure 4. Plot of the chromaticities $\xi_{\mathrm{x}, \mathrm{T}}(\delta \mathrm{p} / \mathrm{p})$, and $\xi_{\mathrm{y}, \mathrm{T}}(\delta \mathrm{p} / \mathrm{p})$ as a function of $\delta \mathrm{p} / \mathrm{p}$. The two curves with the large slope correspond to the functions $\xi_{\mathrm{x}, \mathrm{T}}(\delta \mathrm{p} / \mathrm{p})$ (solid line), and $\xi_{\mathrm{y}, \mathrm{T}}(\delta \mathrm{p} / \mathrm{p}$ ) (dashed line) when only two sextupole families are on.

The other two curves, which are almost horizontal, correspond to the functions $\xi_{\mathrm{x}, \mathrm{T}}(\delta \mathrm{p} / \mathrm{p})$ (solid line), and $\xi_{\mathrm{y}, \mathrm{T}}(\delta \mathrm{p} / \mathrm{p})$ (dashed line) when all four sextupole families (see text) are on. 


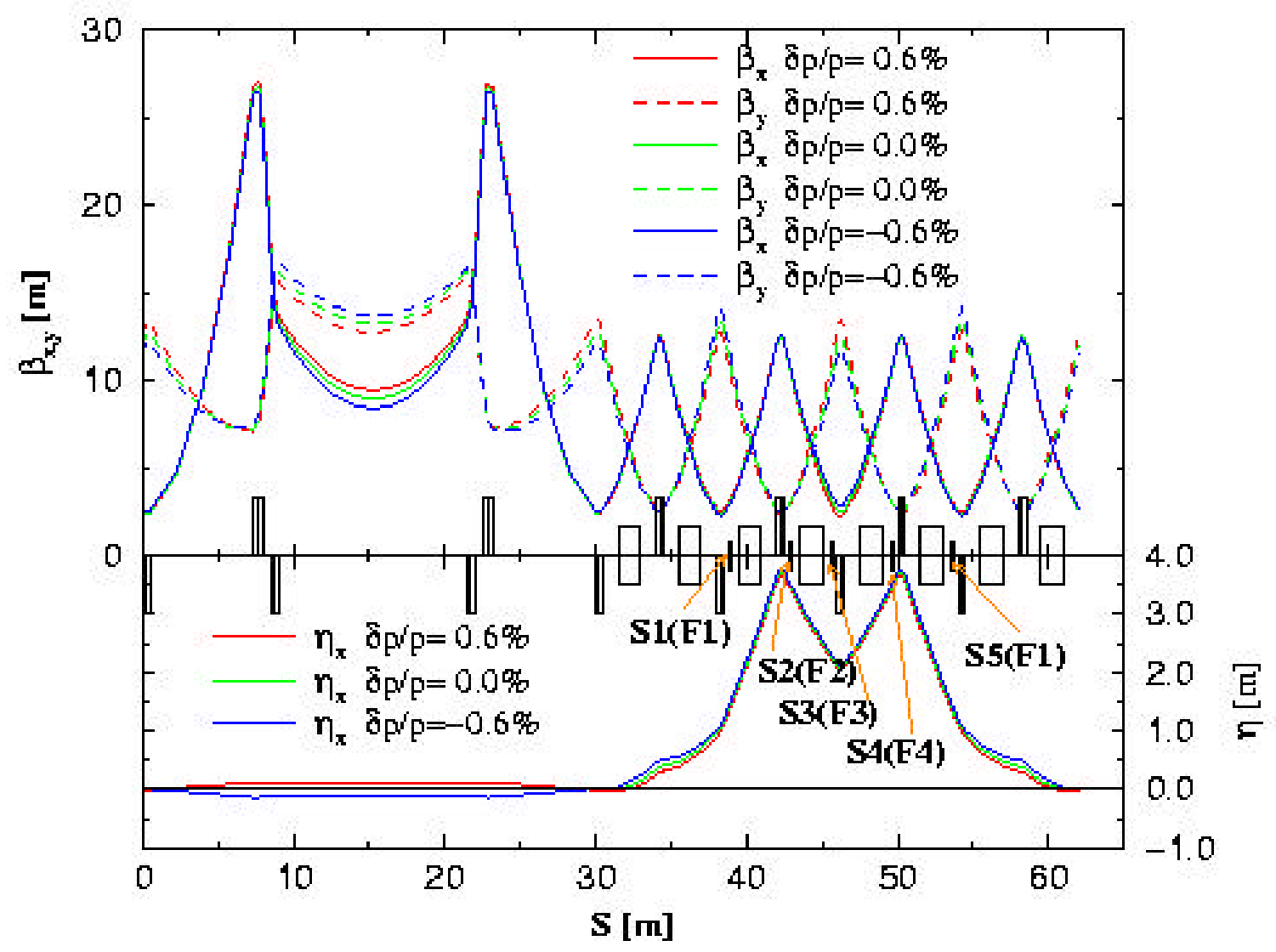

Figure 5. Plot of the optical functions $\beta_{\mathrm{x}}, \beta_{\mathrm{y}}$ and $\eta_{\mathrm{x}}$ for three different momenta $\delta \mathrm{p} / \mathrm{p}$ $(-0.6 \%, 0 \%$ and $+0.6 \%)$ along a superperiod of the SNS ring. The four families of sextupoles $\mathrm{S} 1(\mathrm{~F} 1), \mathrm{S} 2(\mathrm{~F} 2), \mathrm{S} 3(\mathrm{~F} 3), \mathrm{S} 4(\mathrm{~F} 4)$ and S5(F1) are on and set the chromaticities $\left.\xi_{\mathrm{x}, \mathrm{T}}\right|_{\delta \mathrm{p} / \mathrm{p}=0}=0.0$ and $\left.\xi_{\mathrm{y}, \mathrm{T}}\right|_{\mathrm{\delta} / \mathrm{p}=0}=0.0$ (see figure 4 ). This plot shows that the four family sextupoles has almost removed the dependence of the optical functions on $\delta \mathrm{p} / \mathrm{p}$ which is shown on figure 3 . 


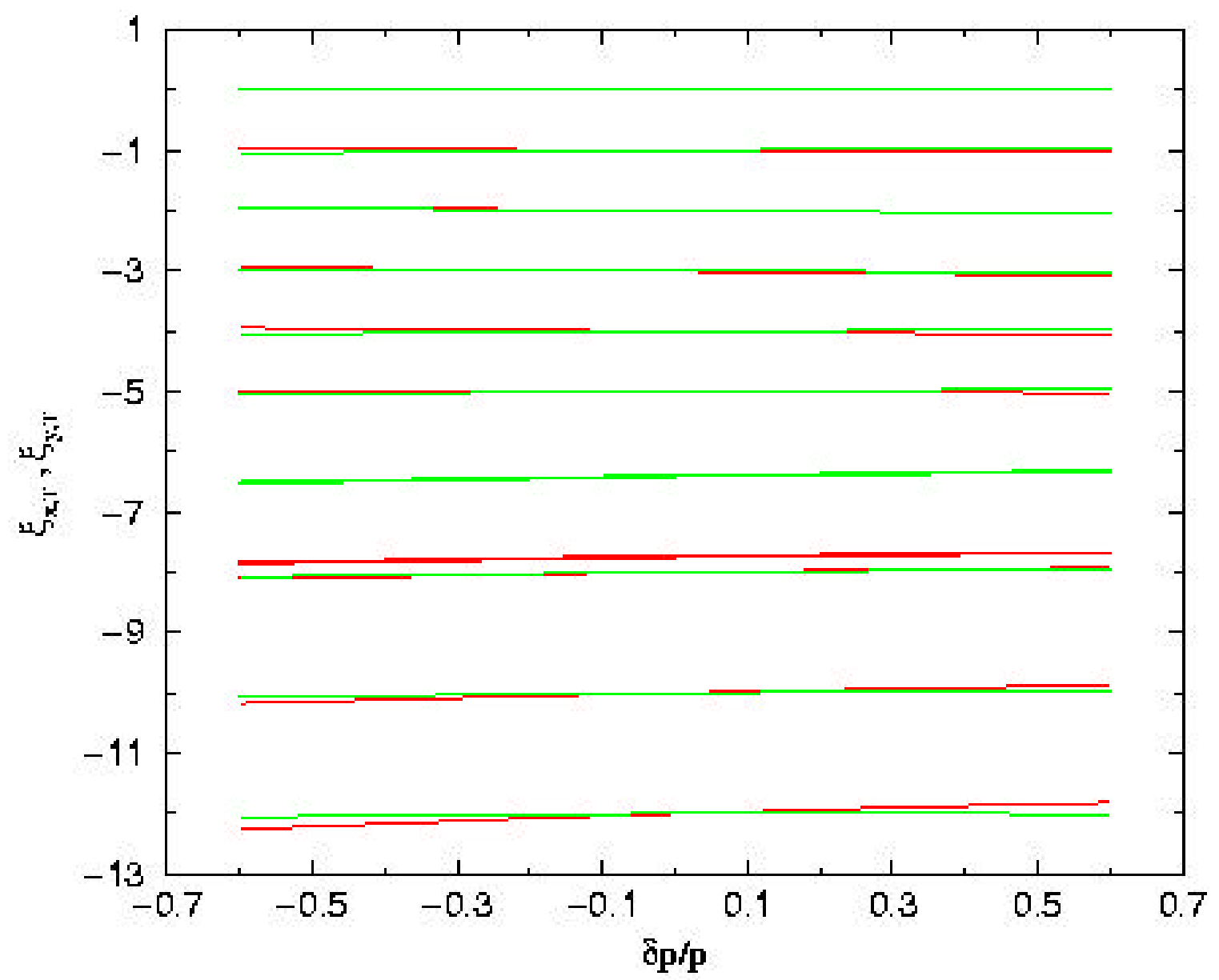

Figure 6: The chromaticity functions $\xi_{\mathrm{x}, \mathrm{y}, \mathrm{T}}(\delta \mathrm{p} / \mathrm{p})$ plotted as a function of the momentum spread $\delta \mathrm{p} / \mathrm{p}$. Each set of horizontal lines (red, green) correspond to a particular set of values of the four family sextupoles shown in culumns 3 to 6 in TABLE I.

The plot shows that there is no strong dependence of the chromaticity functions $\xi_{\mathrm{x}, \mathrm{y}}(\delta \mathrm{p} / \mathrm{p})$ on $\delta \mathrm{p} / \mathrm{p}$. 


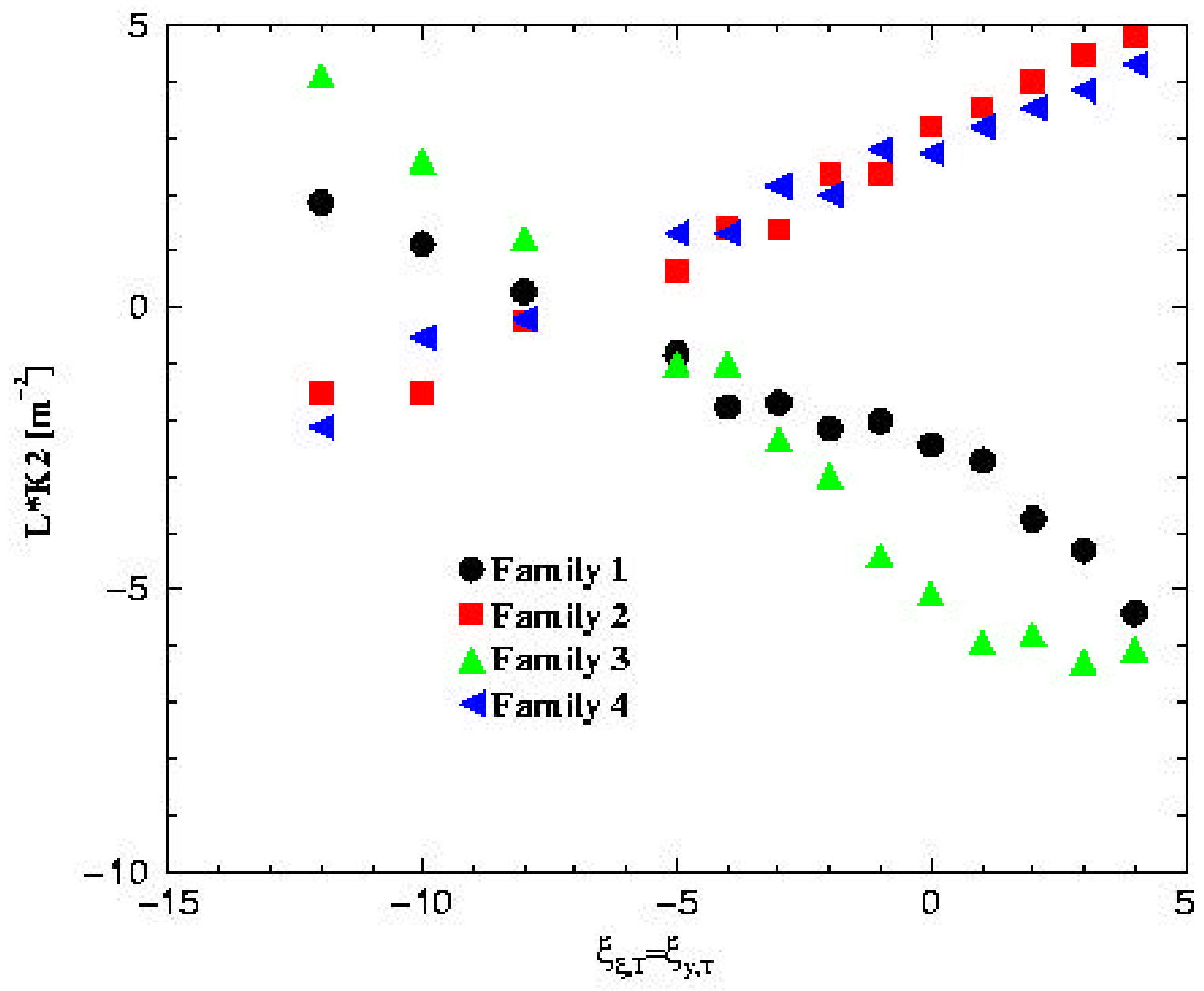

Figure 7: The values of $\mathrm{L}^{*} \mathrm{~K} 2$ (y-axis) of each of the four families of sextupoles that can set a given chromaticity $\left(\xi_{\mathrm{x}, \mathrm{T}}=\xi_{\mathrm{y}, \mathrm{T}}\right.$ ) for the ring, plotted versus the chromaticity. The plot is generated from the values $L^{*} \mathrm{~K} 2$ and $\xi_{\mathrm{x}, \mathrm{T}}$ which were obtained from TABLE I. 


\section{APPENDIX I}

An example of a MAD input file which set the chromaticity and values and also make use of the HARMON module of MAD code (see below) which is carrying the minimization process for the optical compensation

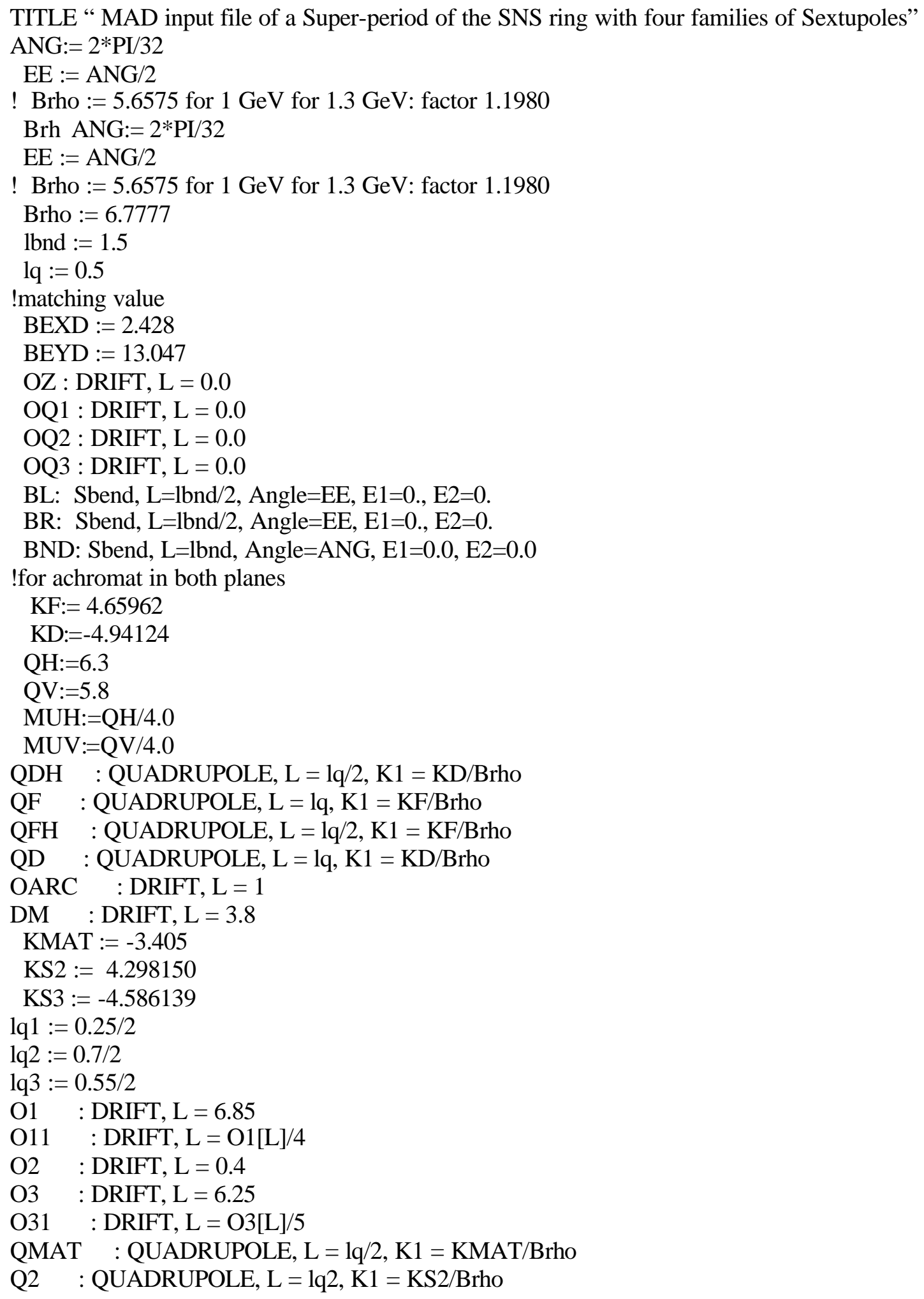




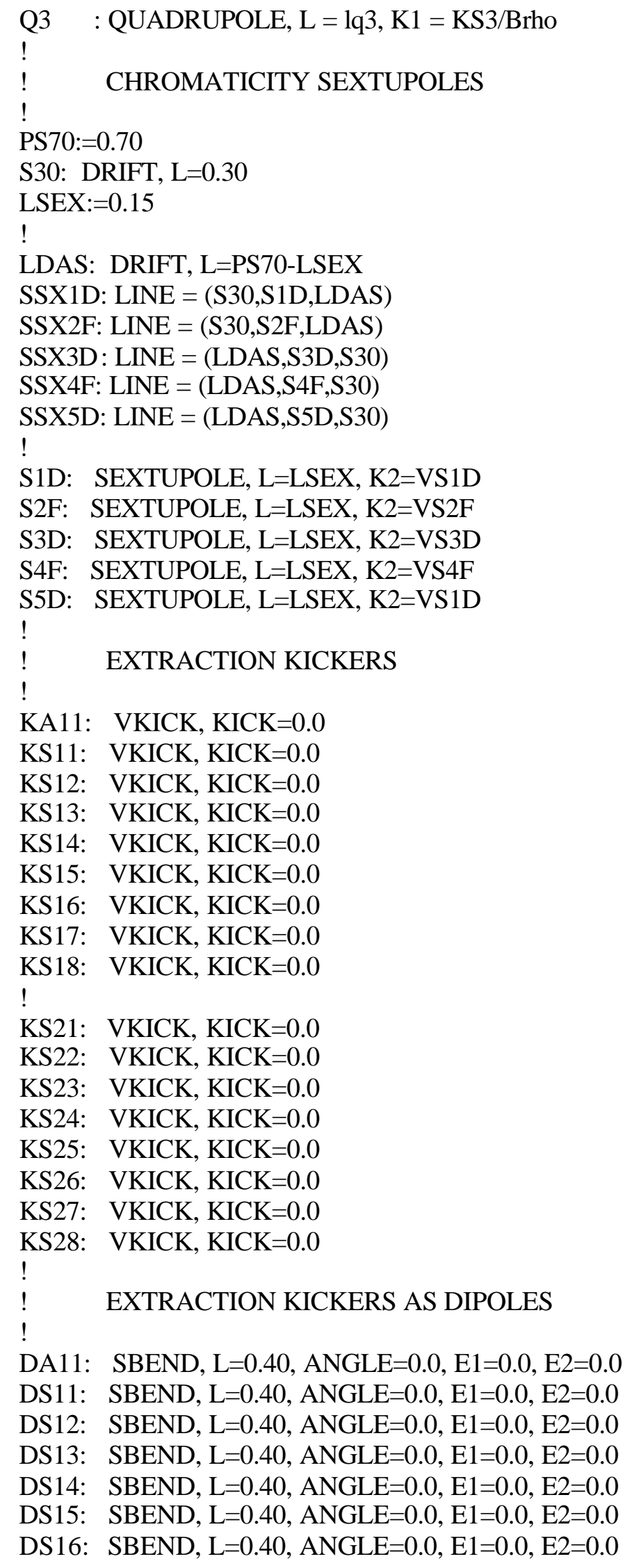




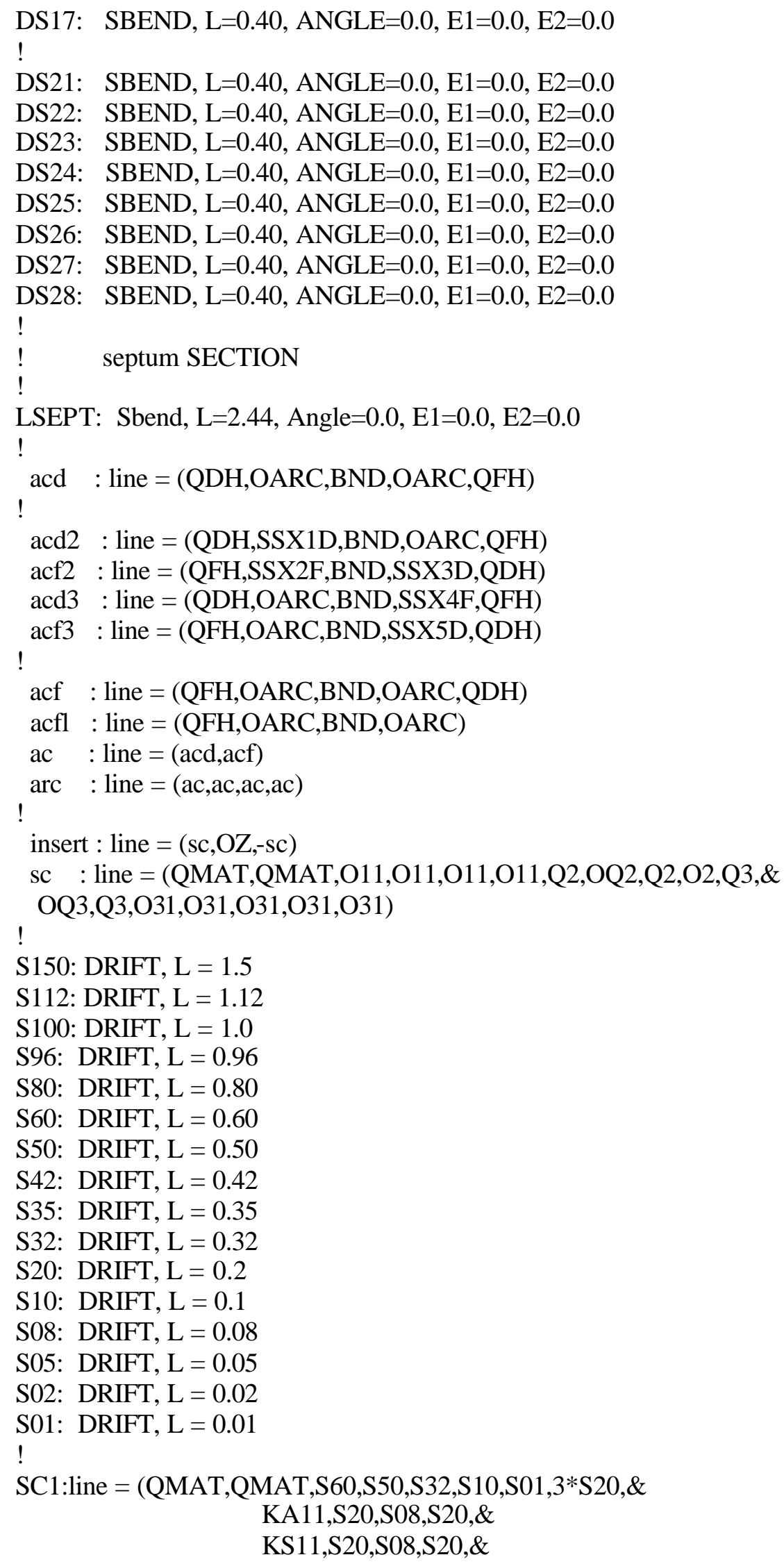




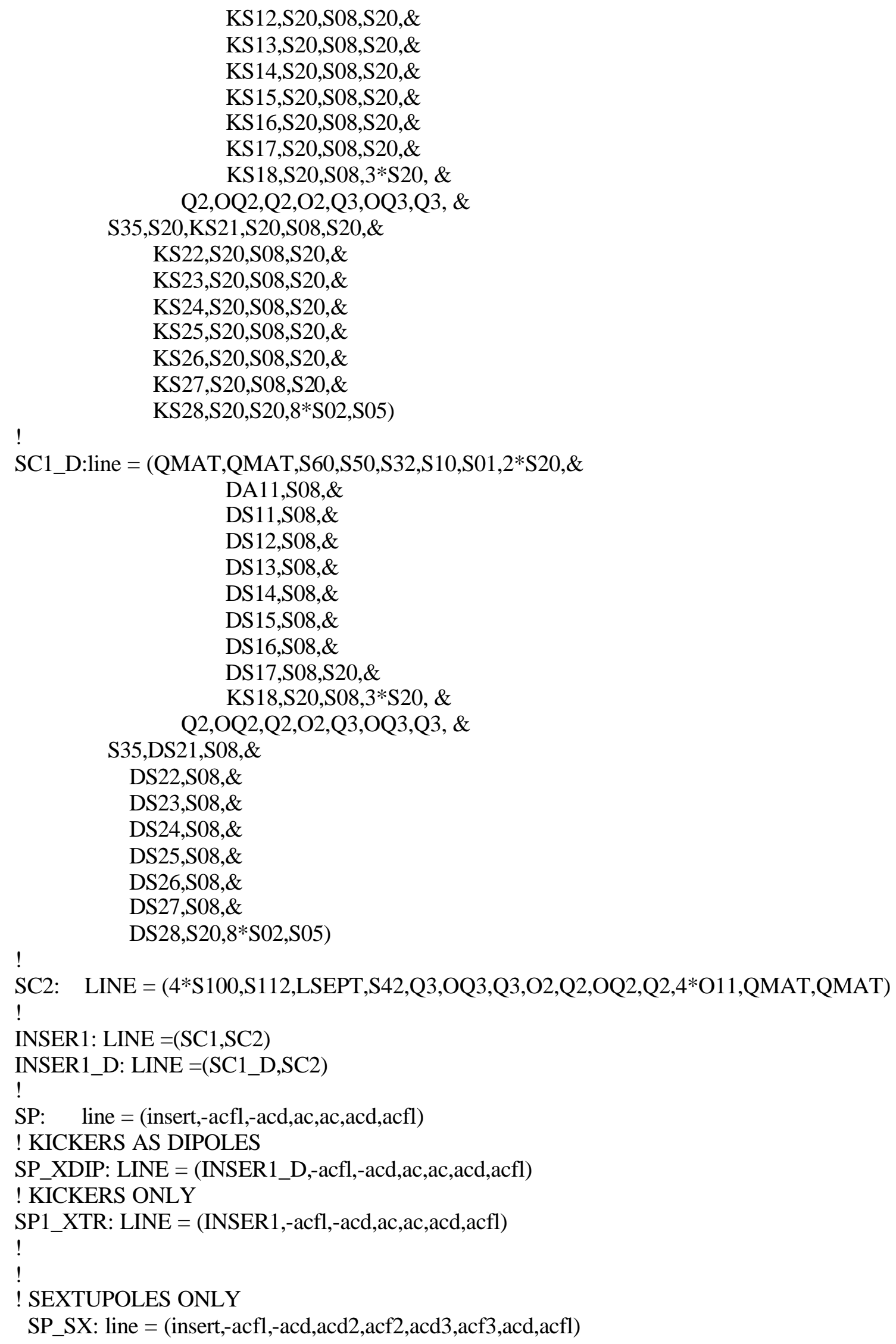




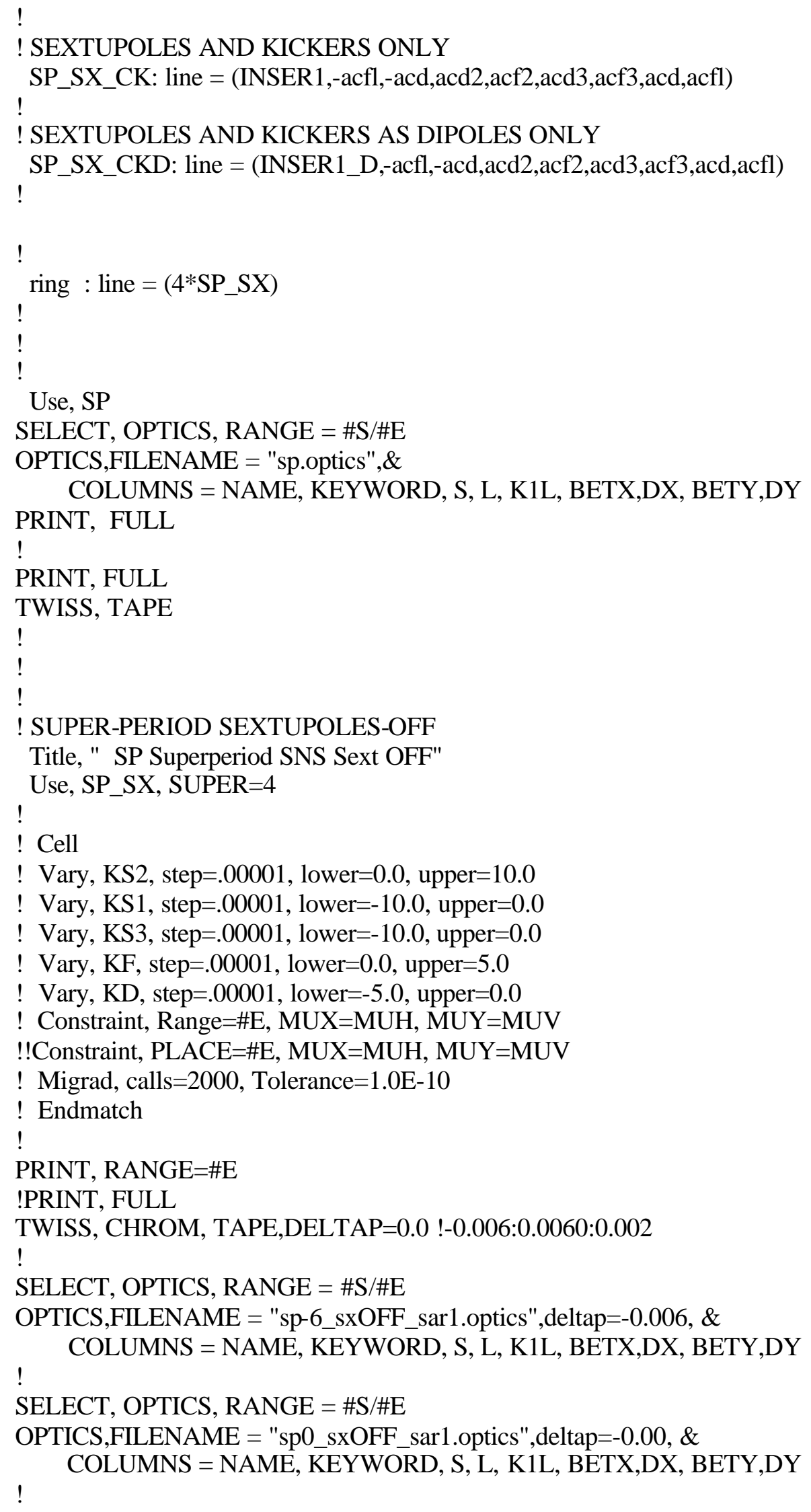




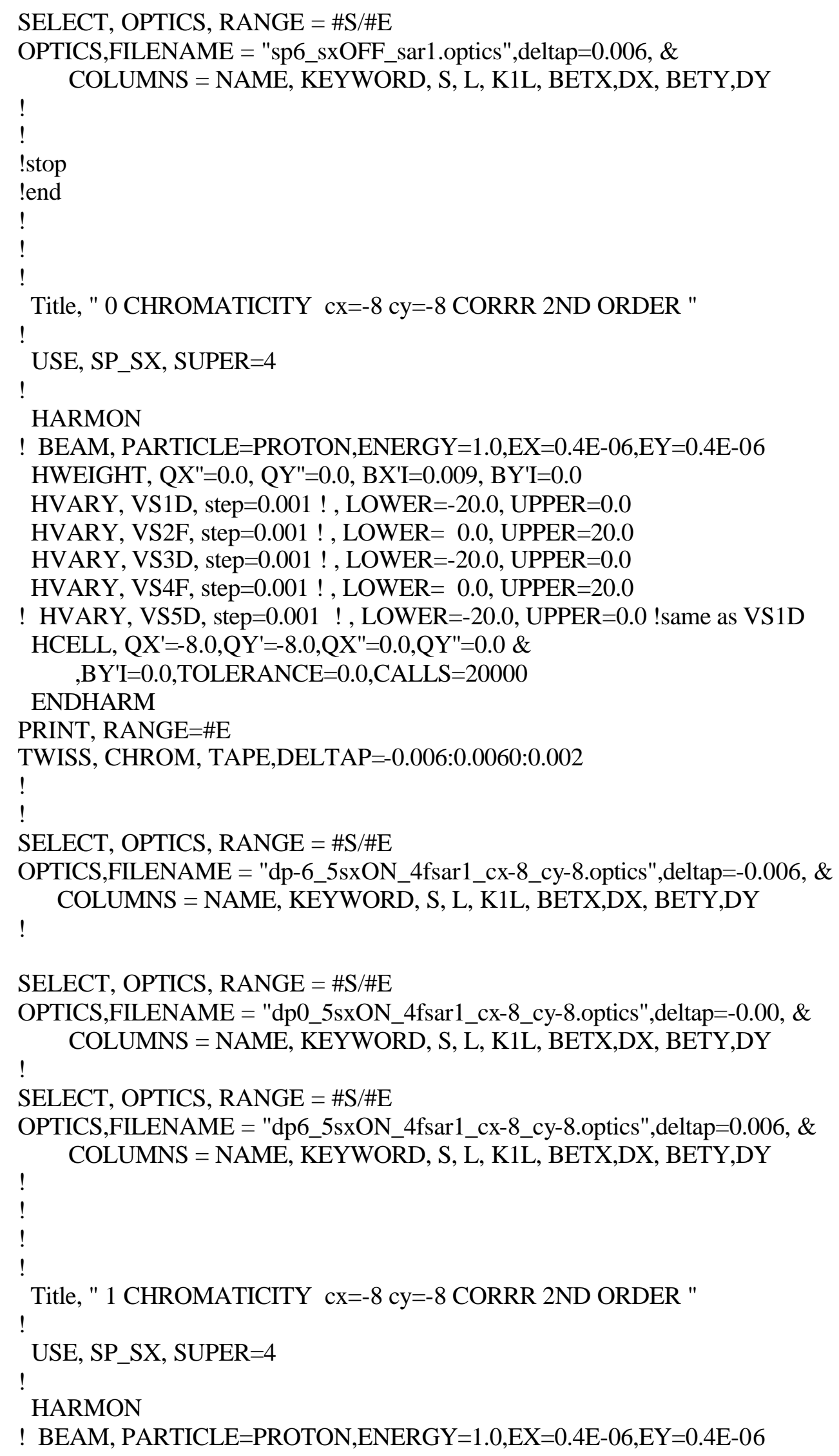


HWEIGHT, QX"=0.0, QY"=0.0, BX'I=0.000, BY'I=0.0

HVARY, VS1D, step $=0.001 !$, LOWER $=-20.0$, UPPER $=0.0$

HVARY, VS2F, step $=0.001 !$, LOWER $=0.0$, UPPER $=20.0$

HVARY, VS3D, step $=0.001 !$, LOWER $=-20.0$, UPPER $=0.0$

HVARY, VS4F, step $=0.001 !$, LOWER $=0.0$, UPPER $=20.0$

! HVARY, VS5D, step $=0.001 !$, LOWER $=-20.0$, UPPER $=0.0$ !same as VS1D

HCELL, QX'=-8.0,QY'=-8.0,QX"=0.0,QY" $=0.0 \&$

,BY'I=0.0,TOLERANCE $=0.0$, CALLS $=20000$

ENDHARM

PRINT, RANGE=\#E

TWISS, CHROM, TAPE,DELTAP=-0.006:0.0060:0.002

!

SELECT, OPTICS, RANGE $=$ \#S/\#E

OPTICS,FILENAME = "dp-6_cx-8_cy-8.optics",deltap=-0.006, \&

COLUMNS = NAME, KEYWORD, S, L, K1L, BETX,DX, BETY,DY !

SELECT, OPTICS, RANGE $=\#$ S/\#E

OPTICS,FILENAME = "dp0_cx-8_cy-8.optics",deltap=-0.00, \&

COLUMNS = NAME, KEYWORD, S, L, K1L, BETX,DX, BETY,DY

!

SELECT, OPTICS, RANGE $=$ \#S/\#E

OPTICS,FILENAME = "dp6_cx-8_cy-8.optics",deltap=0.006, \&

COLUMNS = NAME, KEYWORD, S, L, K1L, BETX,DX, BETY,DY $!$

Title, " 1 CHROMATICITY cx=-10 cy=-10 CORRR 2ND ORDER "

!

USE, SP_SX, SUPER=4

!

HARMON

! BEAM, PARTICLE=PROTON,ENERGY=1.0,EX=0.4E-06,EY=0.4E-06

HWEIGHT, QX"=0.0, QY" $=0.0, \mathrm{BX} \mathrm{I}^{\prime} \mathrm{I}=0.000, \mathrm{BY}^{\prime} \mathrm{I}=0.0$

HVARY, VS1D, step $=0.001 !$, LOWER $=-20.0$, UPPER $=0.0$

HVARY, VS2F, step $=0.001 !$, LOWER $=0.0$, UPPER $=20.0$

HVARY, VS3D, step $=0.001 !$, LOWER $=-20.0$, UPPER $=0.0$

HVARY, VS4F, step $=0.001 !$, LOWER $=0.0$, UPPER $=20.0$

! HVARY, VS5D, step $=0.001$ !, LOWER $=-20.0$, UPPER $=0.0$ !same as VS1D

HCELL, QX'=-10.0,QY'=-10.0,QX"=0.0,QY" $=0.0$ \&

,BY'I=0.0,TOLERANCE $=0.0, \mathrm{CALLS}=20000$

ENDHARM

PRINT, RANGE=\#E

TWISS, CHROM, TAPE,DELTAP=-0.006:0.0060:0.002

!

!

SELECT, OPTICS, RANGE $=\#$ S/\#E

OPTICS,FILENAME = "dp-6_cx-10_cy-10.optics",deltap=-0.006, \&

COLUMNS = NAME, KEYWORD, S, L, K1L, BETX,DX, BETY,DY !

SELECT, OPTICS, RANGE = \#S/\#E 


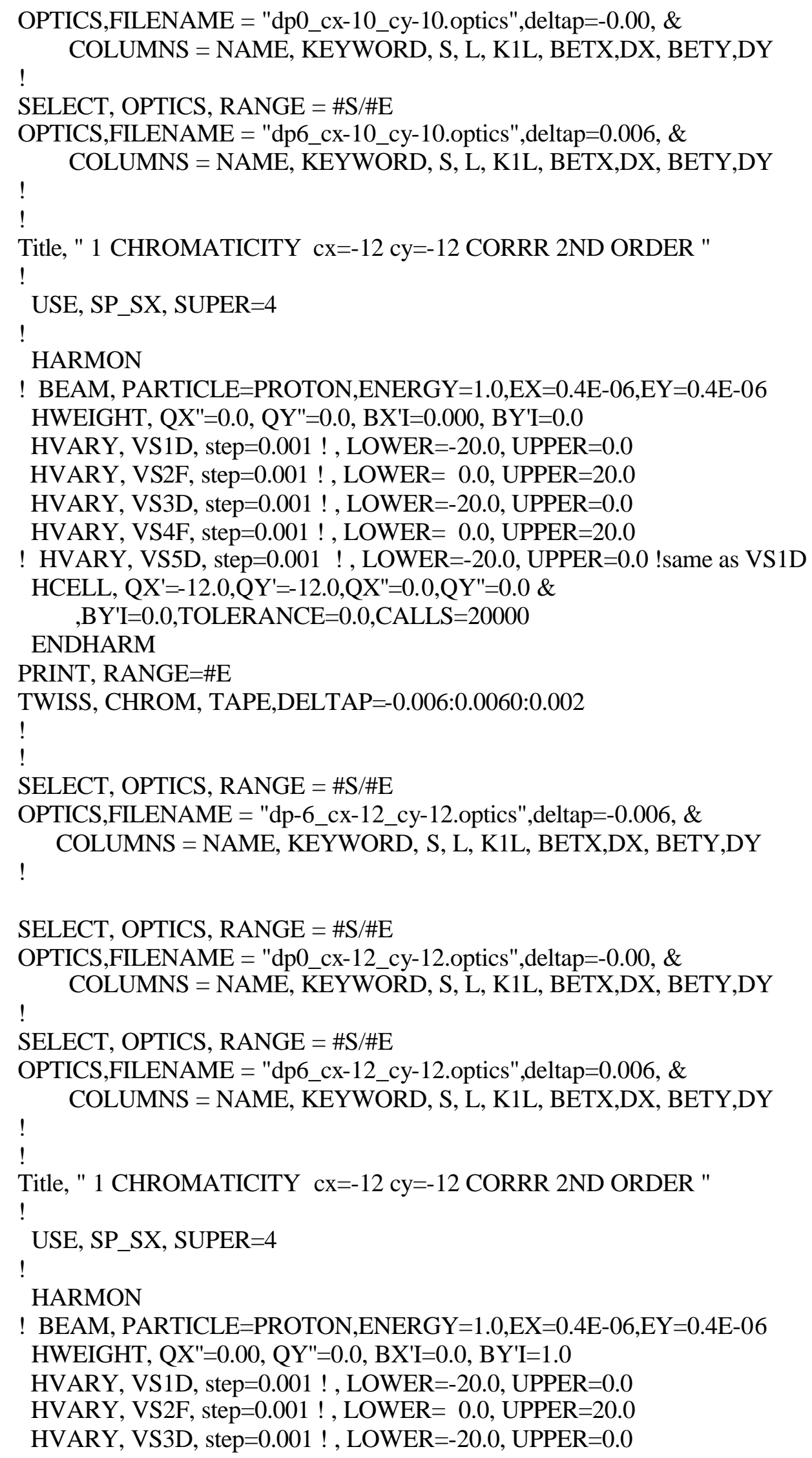


HVARY, VS4F, step $=0.001 !$, LOWER $=0.0$, UPPER $=20.0$

! HVARY, VS5D, step=0.001 !, LOWER $=-20.0$, UPPER $=0.0$ !same as VS1D

HCELL, QX'=-12.0,QY'=-12.0,QX" $=0.0, \mathrm{QY}^{\prime \prime}=0.0 \&$

,BY'I=0.0,TOLERANCE $=0.0, \mathrm{CALLS}=20000$

ENDHARM

PRINT, RANGE=\#E

TWISS, CHROM, TAPE,DELTAP=-0.006:0.0060:0.002

!

SELECT, OPTICS, RANGE $=\#$ S/\#E

OPTICS,FILENAME = "dp-6_cx-12_cy-12.optics",deltap=-0.006, \&

COLUMNS = NAME, KEYWORD, S, L, K1L, BETX,DX, BETY,DY !

SELECT, OPTICS, RANGE = \#S/\#E

OPTICS,FILENAME = "dp0_cx-12_cy-12.optics",deltap=-0.00, \&

COLUMNS = NAME, KEYWORD, S, L, K1L, BETX,DX, BETY,DY

!

SELECT, OPTICS, RANGE $=$ \#S/\#E

OPTICS,FILENAME = "dp6_cx-12_cy-12.optics",deltap=0.006, \&

COLUMNS = NAME, KEYWORD, S, L, K1L, BETX,DX, BETY,DY

!

stop

end 